Marín Sánchez, Eduardo Jesús.

Profesor asociado en la Facultad de Bellas Artes de Altea, Departamento de Arte de la Universidad Miguel Hernández de Elche (UMH).

Investigador del Laboratorio de Interferencias Artísticas y Mediales (IAMLab).

\title{
Semánticas imprevistas en la yuxtaposición de imágenes en movimiento sin relación aparente.
}

\author{
TIPO DE TRABAJO \\ Comunicación \\ PALABRAS CLAVE \\ Videoarte; Docencia; Sinergia.
}

KEY WORDS

Videoart: Teaching; synergy.

\section{RESUMEN}

El diseño de una actividad sencilla para que los estudiantes pudieran iniciarse técnicamente en la asignatura de videoarte, deparó unos resultados artísticos de gran interés. La edición azarosa de videos con contenido perteneciente a dos conceptos o ideas totalmente dispares entre sí, sin relación aparente, tiene el potencial de crear poéticas inesperadas y sinérgicas que no estaban sugeridas en los medios originales. En esta comunicación, describimos las pautas usadas para realizar ese proceso y mostramos alguno de los sorprendentes resultados obtenidos. La reflexión implícita nos retrotrae hasta los estudios teóricos de Kushelov, que sumados al readymade de Duchamp o a la poesía objetual de Brossa, y al concepto apropiacionista, se convierten en una inagotable fuente de la que extraer recursos conceptuales capaces de estimular la creatividad de los estudiantes.

\section{ABSTRACT}

The design of a simple activity so students can begin in the course of video art, threw up some interesting artistic results. The random video editing, with content belonging to two totally different concepts, without apparent connection, has potential to create an unexpected and synergic poetic which are not suggested in the original media. In this paper, we describe the guidelines used to carry out that process and we present some surprising results. The implicit reflection take us to theoretical studies of Kushelov, which added to Duchamp's readymade, or object-based poetry of Brossa, and appropriationist concept, become an inexhaustible source from which to extract conceptual resources capable of stimulating the students' creativity.

\section{CONTENIDO}

\section{INTRODUCCIÓN.}

Ante la evidencia empírica de que los estudiantes accedían a la asignatura de Videoarte de 3 de grado con un nivel irregular respecto a sus habilidades técnicas en el manejo de los programas de edición de video, nos vimos impelidos a desarrollar un programa progresivo de actividades docentes que les permitiera realizar piezas de videocreación desde la mismísima primera clase práctica. 
El primer paso consistió en diseñar una actividad práctica inicial que les sirviera de introducción básica al software de edición (para aquellos estudiantes que aún no supieran manejarlo), y que al mismo tiempo suministrara algún recurso creativo y conceptual que pudiera ser aprovechable para los estudiantes más avanzados. Con en esta motivación en mente, ideamos una tarea práctica a la que denominamos "VideoCollage" haciendo referencia al origen diverso y "encontrado" del material audiovisual del que íbamos a partir.

Al tratarse de una primera clase práctica, los estudiantes acudían sin haber tenido tiempo de realizar ninguna grabación de video original con la que comenzar a editar. La solución fue solicitarles que, en la misma clase y a través de internet, localizaran y descargaran el material adecuado para realizar su primera pieza de videocreación. Para fomentar la originalidad formal y conceptual de sus piezas, decidimos que cada alumno debía elegir sus propios videos, así que les marcamos unas pautas que les permitieran dirigir su búsqueda canalizando sus intereses personales y favoreciendo la consecución de resultados artísticos aceptables.

La práctica de Videocollage con la que arrancamos la asignatura puede iniciarse tras apenas una hora de aprendizaje de las herramientas básicas de edición de video por corte. En ella el estudiante descubre por sí mismo la dialéctica que se establece al yuxtaponer distintas imágenes y audios capaces de generar ritmos y semánticas imprevistas que, tras un posterior proceso de refinamiento, pueden dar lugar a una auténtica poética audiovisual.

Así pues, los principales objetivos de esta práctica docente quedaron definidos del siguiente modo:

1.- Los estudiantes deben poder trabajar de manera práctica en una pieza de videocreación desde el primer momento, independientemente del grado de conocimiento del género y su técnica.

2.- El proceso de la práctica debe instruir al estudiante en recursos técnicos y conceptuales relativos a la materia de la asignatura.

3.- La práctica debe ser una herramienta creativa que facilite el hallazgo de nuevas semánticas y poéticas.

En el Anexo de esta comunicación se pueden consultar las instrucciones escritas dadas a los estudiantes en el momento de iniciar la actividad del VideoCollage.

Se puede visualizar una selección de los trabajos de VideoCollage realizados en la UMH en la lista de reproducción de Youtube VIDEOCOLLAGE UMH: https://www.youtube.com/watch?v=LYulZtvcjWU\&list=PLv05NdORj-Zw4OUSQRDxr9GwG1XMhadFX

\section{DESARROLLO: Referencias y Metodología del proceso.}

Dado el generalizado desconocimiento detectado entre los estudiantes acerca del género de la videocreación, decidimos buscar unos referentes cuya aplicación práctica surgiera de modo casi inconsciente durante el proceso que debíamos pautar, y que contribuyera a dibujar un marco donde situar el videoarte. Estos referentes se relacionan con partes muy determinadas del proceso de creación del VideoCollage. Trataremos paralelamente tanto esos referentes como la metodología propuesta para relizar dicho VideoCollage.

\subsection{Dadaísmo: Los readymade de Marcel Duchamp.}

La elección de los readymade está siempre basada en la indiferencia así como en una carencia total de buen o mal gusto. ${ }^{1}$

Esta idea de Duchamp es la inspiración del método escogido para localizar el material audiovisual desde el que componer VideoCollage.

Si la poética tradicional se centraba en añadir una ornamentación retórica al discurso, la nueva poeticidad dadaísta consistió en una revalorización total del discurso y de cualquiera de sus componentes ${ }^{2}$. Es por eso que Schwitters llega a afirmar que "a la declamación le da igual si su material es o no poesía, se puede declamar el alfabeto, que en sí no es más que una forma práctica, y conseguir un resultado artístico". ${ }^{3}$

\footnotetext{
${ }^{1}$ CABANNE, PIERRE. Conversaciones con Marcel Duchamp. Editorial Anagrama, Barcelona, 1972, pág. 41. ISBN: 9788493491659

2 JAKOBSON, ROMAN. Ensayos de lingüística general. Seix Barral, Barcelona 1975, pág. 394.

${ }^{3}$ SCHWITTERS, KURT. La poesía consecuente (Konsecuente Dichtung), 1924 Publicado en: G. Zeitschrift hir elementare Gestaltung, Berlín, 10 año, nº 93, junio de 1924, IVAM, Valencia, 1995
} 
Siguiendo ese concepto subyacente de que cualquier material es susceptible de ser transformado en arte ${ }^{4}$, que sería asumido posteriormente por Fluxus (los pioneros del videoarte), intentaríamos realizar ese acto de creación apropiándonos de videos encontrados casi azarosamente en internet.

Durante la búsqueda de esos videos, y con el fin de evitar cualquier atisbo de intencionalidad argumental que alejara la pieza del terreno del videoarte (el videoarte no encaja bien con la narrativa convencional), decidimos aplicar un cierto grado de indeterminación que nos obligara a "encontrar resultados" antes que a buscarlos. Para ello los videos elegidos debían de proceder a partes iguales de dos ideas o conceptos sobre las que el estudiante fuera incapaz de encontrar una relación lógica.

\title{
2.2. Dadaísmo: El azar como herramienta de creación.
}

Los dadaístas introdujeron el azar como elemento creador imprevisible y repleto de frescura. Para ellos, el aparente desorden inherente al caos esconde una realidad que extiende los horizontes de la conciencia humana. Hans Arp realizó la obra Según las leyes del azar recortando pedazos de papel de colores, para dejarlos caer después, sin intención, sobre un soporte, y permitir que el azar compusiera la obra plástica. En la misma línea, en 1920 Tristan Tzara escribió las instrucciones para hacer un poema dadaísta, texto que nos ha servido como inspiración fundamental de la práctica del VideoCollage:

\author{
Tome un periódico. \\ Tome unas tijeras. \\ Elija en el periódico un artículo de la extensión que usted quiera dar a su poema. \\ Recorte el artículo. \\ Recorte en seguida con cuidado cada una de las palabras que forman el artículo y métalas en una bolsa. \\ Agítela suavemente. \\ Extraiga luego cada trozo, uno tras otro. \\ Copie concienzudamente en el orden en que hayan salido de la bolsa. \\ El poema será la viva imagen de usted, y usted será un escritor infinitamente original y de una exquisita sensibilidad, aunque el vulgo \\ no lo comprenda.
}

Ésta fue la forma de composición adaptada para nuestra práctica, sustituyendo el periódico por los videos y usando el software de edición de video en lugar de las tijeras. El propósito es crear un primer montaje azaroso en busca de estructuras rítmicas, visuales y sonoras lo más variadas posibles.

El material obtenido a partir del azar dadaísta, necesita en este momento ser analizado y valorado. Hay que localizar y apreciar estructuras visuales y sonoras consistentes y, sobre todo, interpretar la información semántica que las diferentes yuxtaposiciones de imágenes nos transmiten. A este respecto, nos dice Duchamp:

El artista no es el único que consuma el acto creador pues el espectador establece el contacto de la obra con el mundo exterior, descifrando e interpretando sus profundas calificaciones para añadir entonces su propia contribución al proceso creativo.

Marcel Duchamp ${ }^{6}$

El papel activo del espectador es básico para la comprensión de las nuevas semánticas generadas, y nos resulta fundamental el conocimiento de las investigaciones de Lev Kushelov en el campo del montaje cinematográfico, así como las Teorías de la Gestalt que ayudan a decodificar las relaciones que se establecen entre las distintas imágenes yuxtapuestas.

\subsection{El Efecto Kushelov.}

A través del montaje era posible crear un nuevo lugar terrestre que no existía de otra manera. ${ }^{7}$

\footnotetext{
${ }^{4}$ FERRANDO, BARTOLOMÉ. El Arte Intermedia, convergencias y puntos de cruce. Edit. Universidad Politécnica de Valencia, Valencia, 2003 pág. 33.

${ }^{5}$ TZARA, TRISTAN. Manifiesto sobre el amor débil y el amor amargo, VIII, en A l'antiphilosophe. En Littérature num. 15. Julio-Agosto de 1920.

${ }^{6}$ Cita extraída de FERRANDO, BARTOLOMÉ. El arte de la performance: elementos de creación, Editorial: Mahali Ediciones (Stella Cometa, S.L.), 2009. ISBN: 978-84-613-1524-6, Pg. 87.

${ }^{7}$ MARINIELLO, SILVESTRA (1992). El cine y el fin del arte : teoría y práctica cinematográfica en Lev Kuleshov. Madrid: Cátedra. ISBN 8437610699 .
} 
El cineasta y teórico ruso Lev Kushelov (1899-1970) realizó en los años 20 una experiencia de montaje cinematográfico en la que demostraba que la semántica de un plano afectaba de manera radical a la semántica de aquellos otros planos entre los se inserta:

Kushelov montó tres secuencias distintas. En cada una de ellas, tras una misma toma de un actor (Ivan Mozzhukhin) con expresión neutra, insertaba alternativamente las imágenes de un plato de sopa, un ataúd con una niña y una mujer recostada. Pese a la monotonía gestual del actor, los espectadores de estas secuencias percibían en su expresión ciertos cambios expresivos condicionados por el carácter del plano que le seguía.
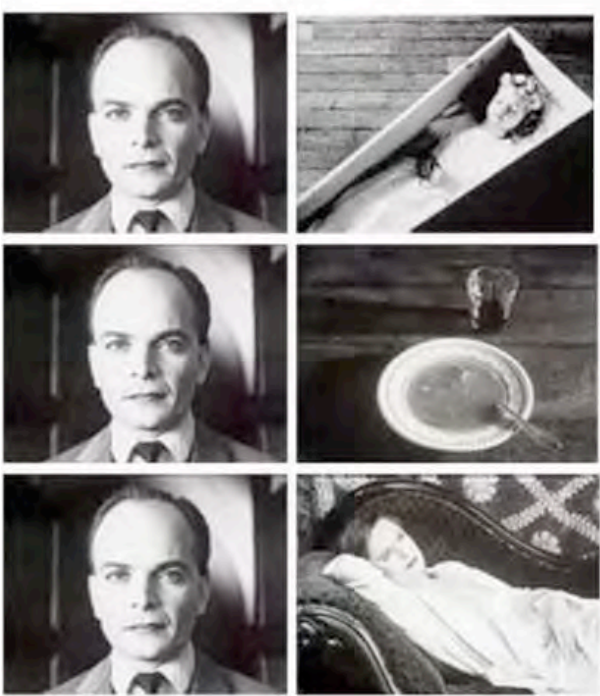

Cara neutra + ataúd con niña = Tristeza

Cara neutra + plato de sopa $=$ Hambre

Cara neutra + mujer recostada $=$ Deseo

\subsection{La Gestalt.}

Llegados a este punto, parece obligada una cita a la Gestalt. Según esta psicología, podríamos decir que el cerebro, en un constante intento de dar sentido a los estímulos que recibe, relaciona las secuencias de imágenes y las reinterpreta como una nueva totalidad: "el todo es más que la suma de las partes".

Dos imágenes sin conexión aparente, cada una de ellas con una semántica propia, se unen y generan una semántica nueva. ¿Por qué sucede este fenómeno?

En ocasiones las Leyes Generales de la Gestalt ${ }^{9}$ nos pueden ayudar a comprender ese proceso, aunque debemos tener en cuenta que estas leyes no actúan de forma individual, sino combinadamente e interfiriéndose las unas a las otras.

De este modo, por ejemplo, podemos aplicar el "Principio general de figura y fondo", al siguiente ejemplo de VideoCollage, pues la tecnología nos permite superponer distintos videos y conseguir que se comporten como figura o fondo indistintamente.

\footnotetext{
${ }^{8}$ KOHLER, WOLFANG. Gestalt psychology: an introduction to new concepts in modern psychology. New York: Liveright. Norton 1992 reprint: ISBN 978-0871402189

${ }_{9}^{9}$ LEONE, GUILLERMO. Leyes De la Gestalt. 1998-2011En disposición web: www. gestalt-blog.blogspot.com
} 


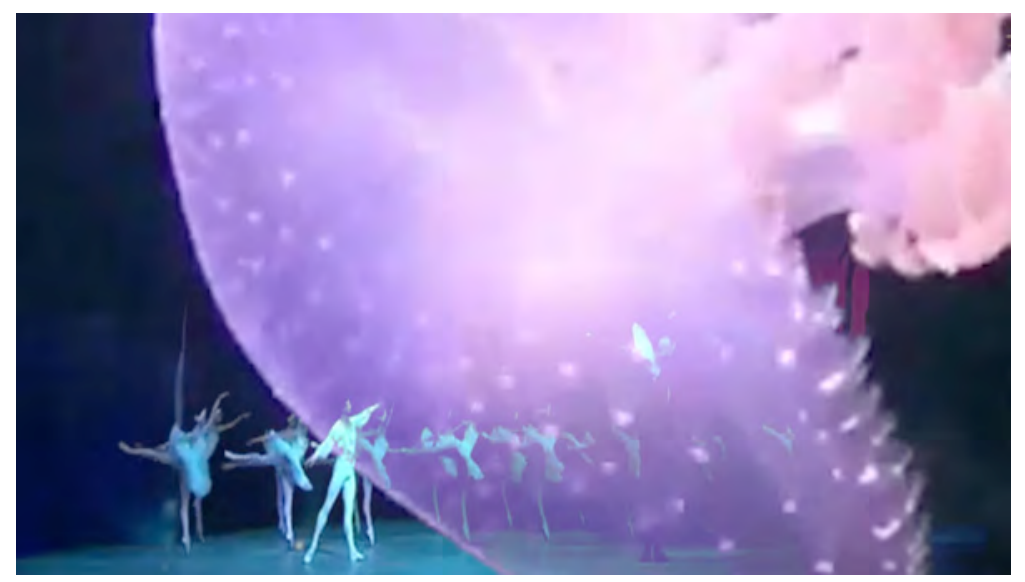

Fix swan, Claudia García Martí, VideoCollage, 2015. https://youtu.be/20s60wnPIks

La "Ley de similaridad" nos permite asociar elementos similares:

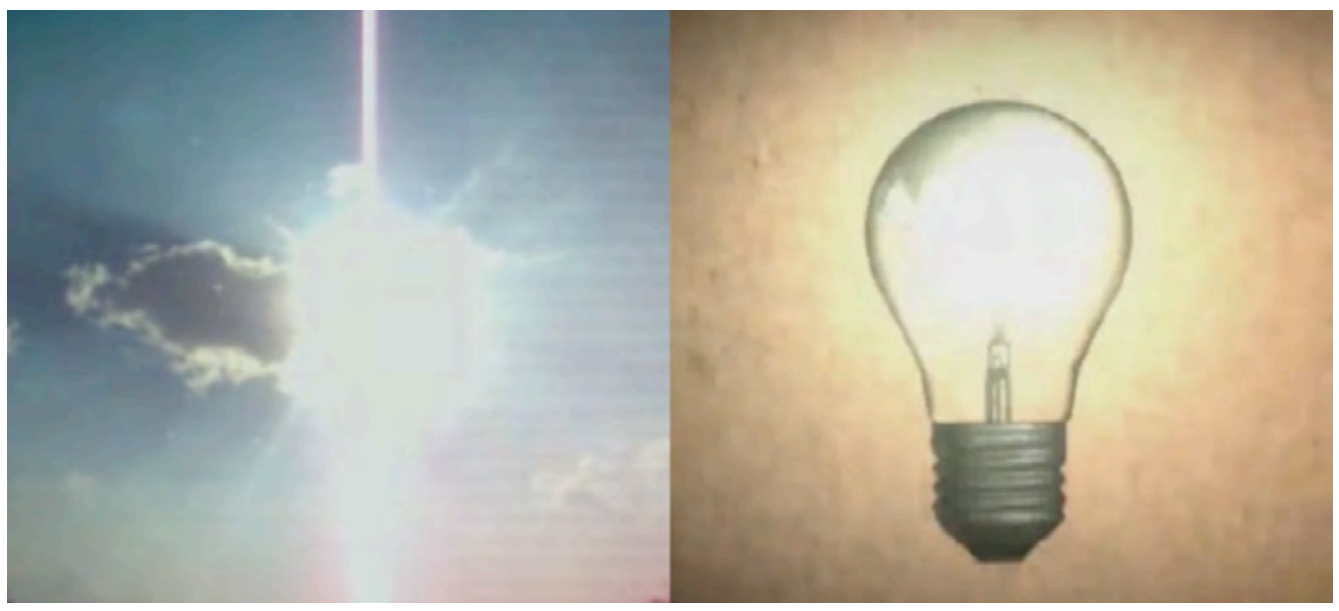

Simetría, Silvia Guillén, Videocollage, 2012. https://youtu.be/6xixGt5EPXc
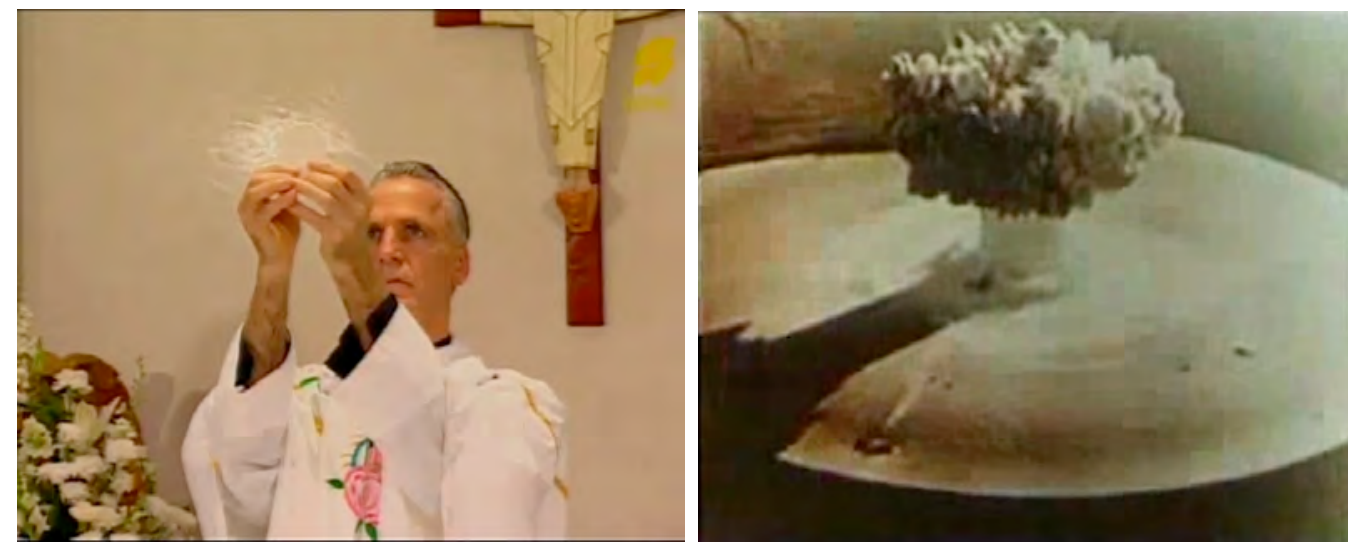

Pesambre, José Antonio López Zamora, VideoCollage, 2013. https://youtu.be/hwO2lkwy_CE

La "Ley del movimiento o destino común",íntimamente relacionada con el concepto de raccord o continuidad cinematográfica, asocia las imágenes basándose en las direcciones de los movimientos. 

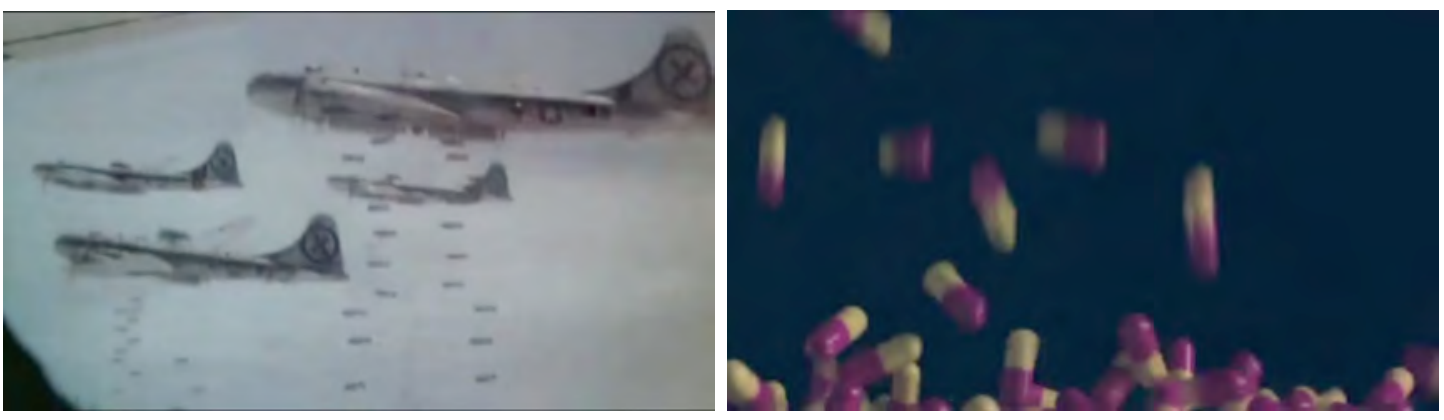

Adrenalina, Celia Ivars, VideoCollage, 2013. https://youtu.be/JACu0ErMzlg

\subsection{BREVE APUNTE SOBRE EL AUDIO.}

Mención especial merece el uso del sonido en esta actividad, que por cuestiones de espacio no abordaremos en profundidad en esta comunicación pero que sin duda se merece una propia. Tan sólo apuntar que en la edición del VideoCollage, el audio es susceptible de ser usado de muy variadas y creativas maneras: manteniendo el sonido original de cada plano, intercambiando los sonidos originales de los planos, distorsionándolo mediante las herramientas digitales, acumulando varios sonidos simultáneos, extrayéndolo para dejar paso al silencio, convirtiéndolo en un tercer concepto que da una vuelta de tuerca más al VideoCollage, etc.

En cualquier caso, queremos dejar constancia de que la aportación del sonido a la transmisión de esas semánticas inesperadas es fundamental y absolutamente determinante.

\subsection{POÉTICA EXPERIMENTAL.}

Cuando la yuxtaposición de esas imágenes se convierte en poética nos empezamos a aproximar al videoarte.

Pues el videoarte es un género que bebe y vive de la poética.

Y es en la poesía experimental donde encontramos esa poética imprevista y sorpresiva que nos interesa.

En esta comunicación personificaremos esa poética Joan Brossa, auque consideramos que todo el movimiento de la Poesía experimental iniciado con Mallarmé y que evolucionó con el futurismo, dadaísmo, letrismo, poesía concreta, Fluxus y demás poetas contemporáneos, tienen un gran campo de influencia en la práctica del VideoCollage. El espíritu de la poética experimental puede empapar al VideoCollage con sus juegos visuales, semánticos, sonoros, textuales, sus ilusiones de movimiento y acción o su aparente falta de lógica capaz de transportarnos a estados de conciencia casi alterados.

Brossa practicó la descontextualización de los más variados objetos, así como su recombinación, creando un universo que se ha convertido en referente obligado de la poesía experimental contemporánea. Uno de los grandes méritos de Brossa ha sido su habilidad para descubrirnos que los objetos más corrientes poseen significados ocultos por su semántica convencional. Así lo evidencia en sus poemas visuales o poemas objeto, como sucede en su pieza País (1988), donde la suma de un balón de fútbol y una peineta dan como resultado una irónica descripción de la España de su época. ${ }^{10}$

Aprovechemos el espíritu de Joan Brossa para concluir esta comunicación con una selección de semánticas imprevistas surgidas al abrigo de las prácticas de VideoCollage realizadas en la Asignatura de VideoArte de la Facultad de Bellas Artes de Altea (UMH).

\footnotetext{
${ }^{10}$ BROSSA, JOAN. Brossa 1986-1991, poemas objeto e instalaciones [Exposición]; 30 enero-12 marzo, Sala Diputación de Huesca., Diputación de Huesca D.L. Huesca, 1991. (ISBN: 84-86978-74-2)
} 

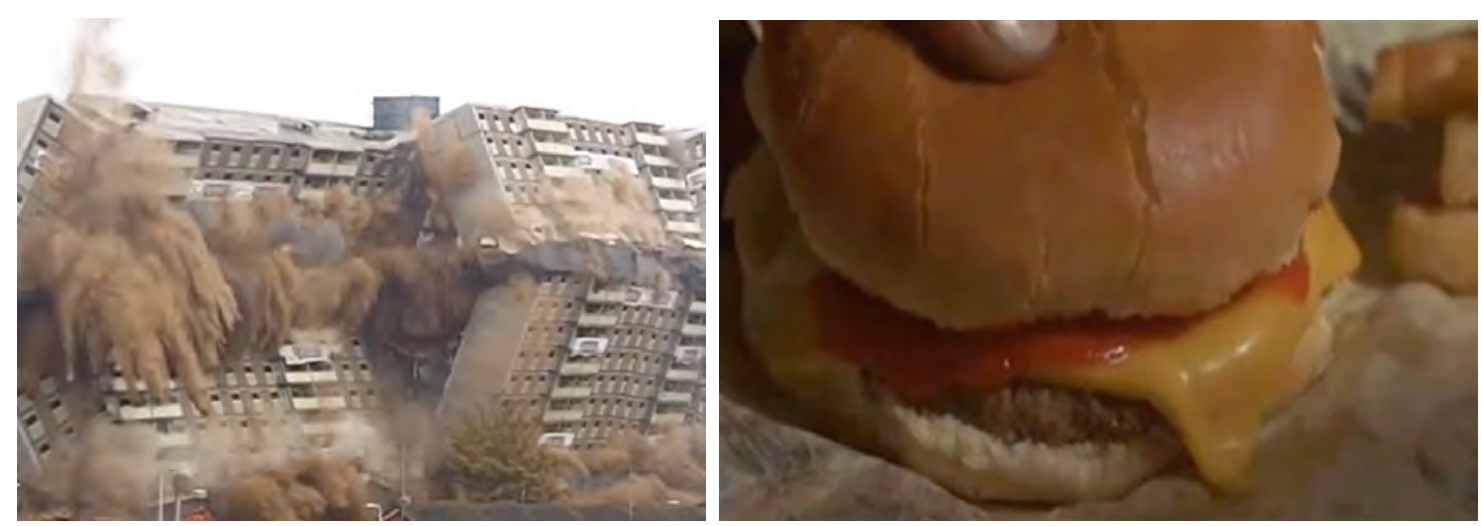

"Escombros deliciosos", David Mansilla, VideoCollage, 2013. https://youtu.be/_CSxV0xVyaw
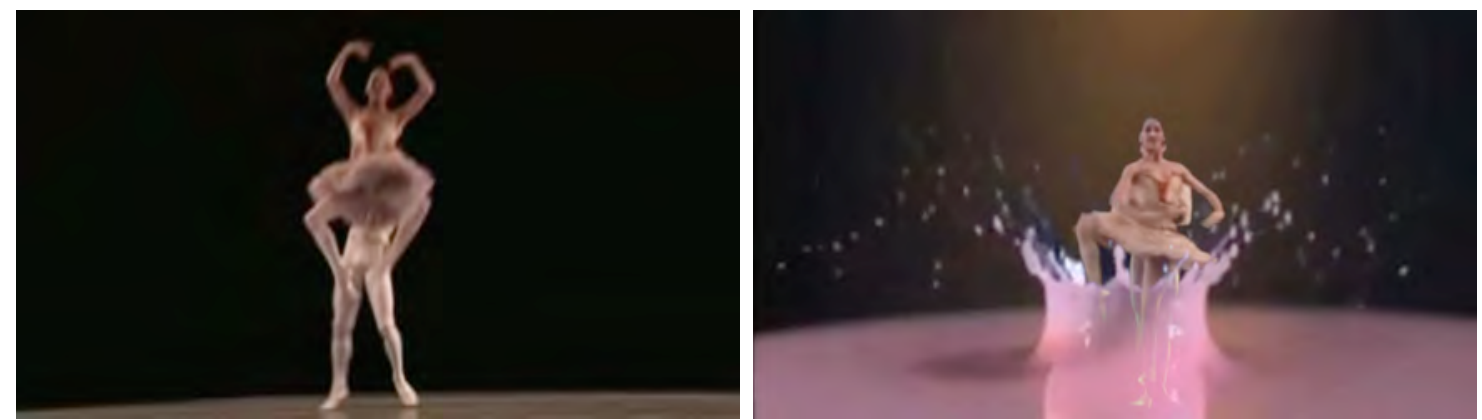

“La expresión de la vida", Irene Cano, VideoCollage, 2014. https://youtu.be/1e6sBdHYaxw
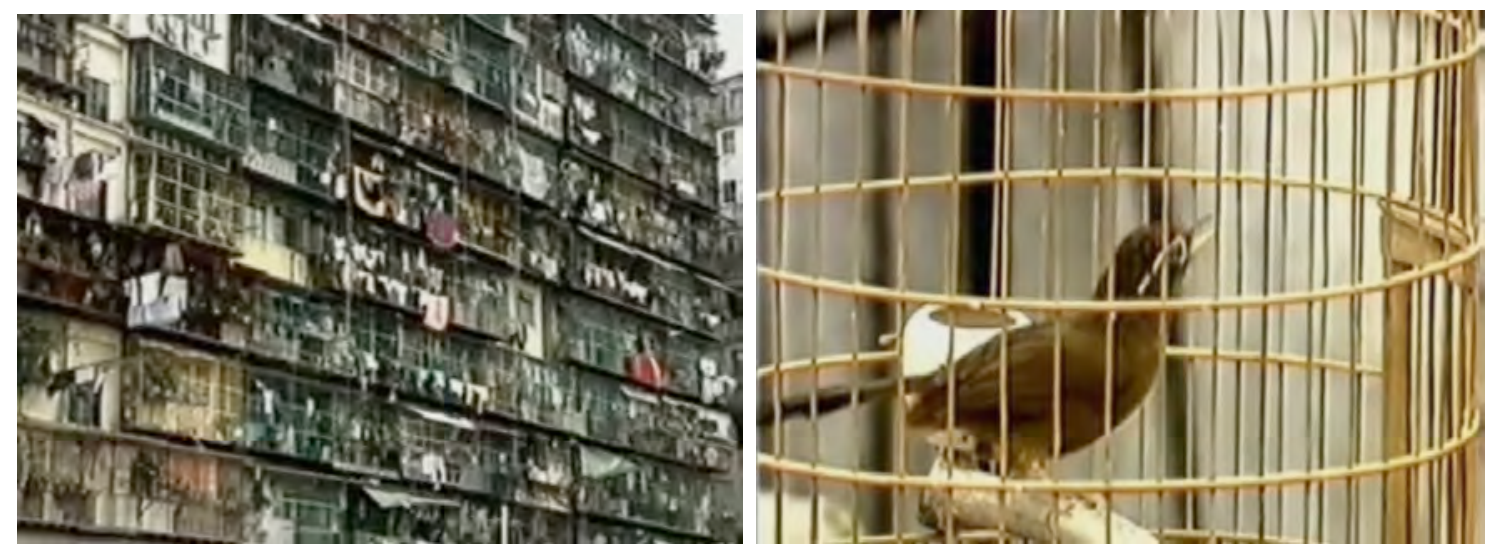

“Build your cages", Ricardo Casal Díaz, VideoCollage, 2014. https://youtu.be/LYulZtvcjWU
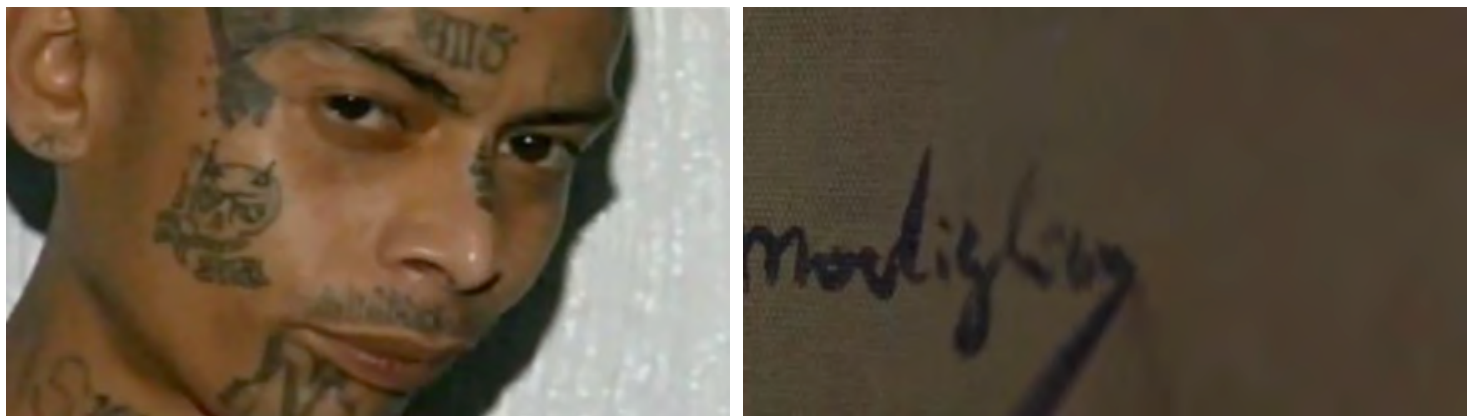

“Ora et labora”, Roberta Cotterli, VideoCollage, 2014. 

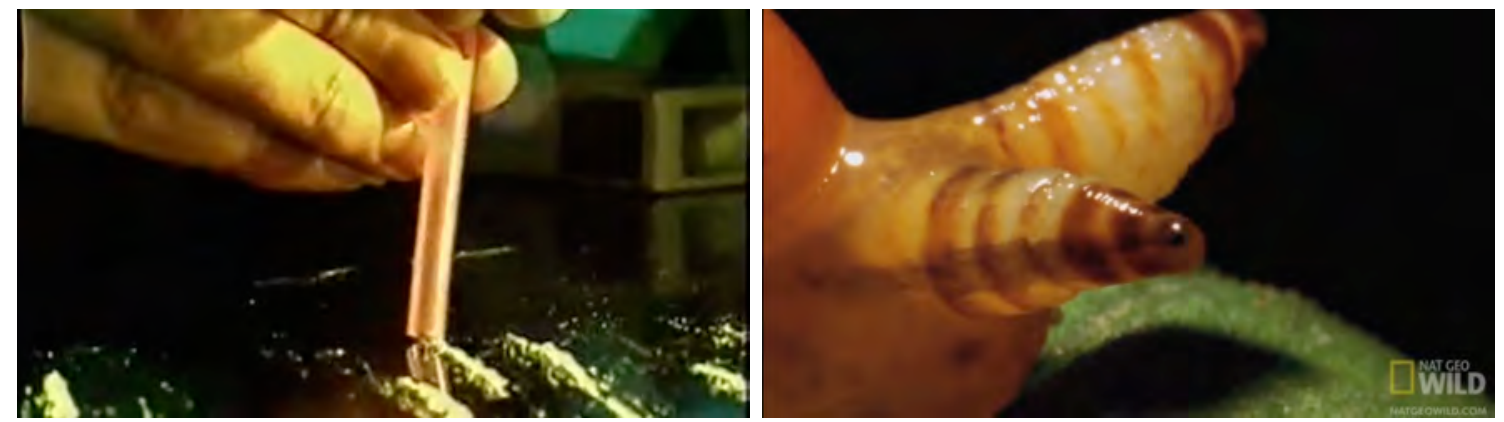

“Algún título", Lois Jansen, VideoCollage, 2014. https://youtu.be/N3bgNS7lull
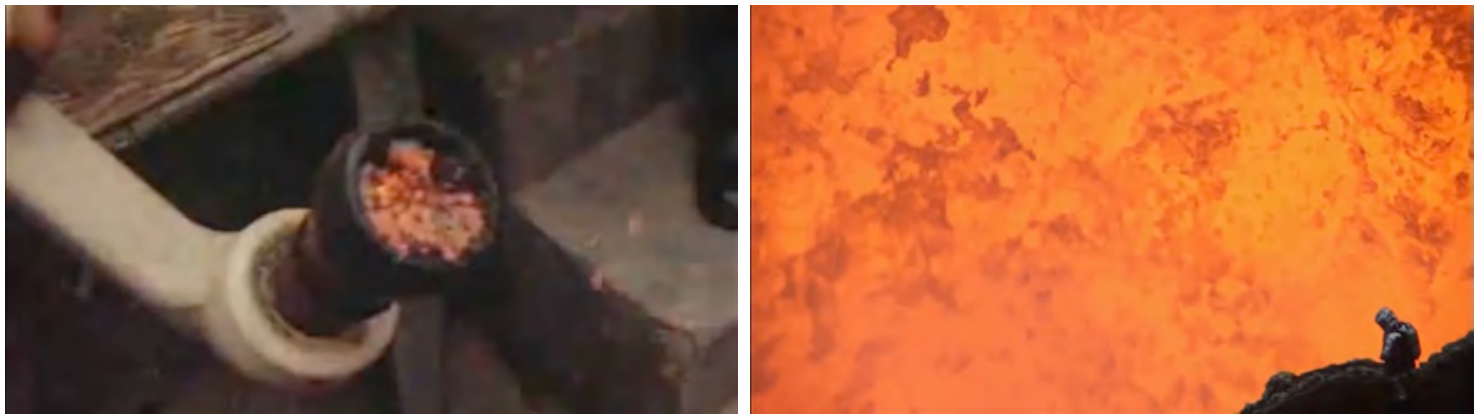

"Boblcano", Toni Navarro, VideoCollage, 2014. https://youtu.be/NOrrQCrxVQI
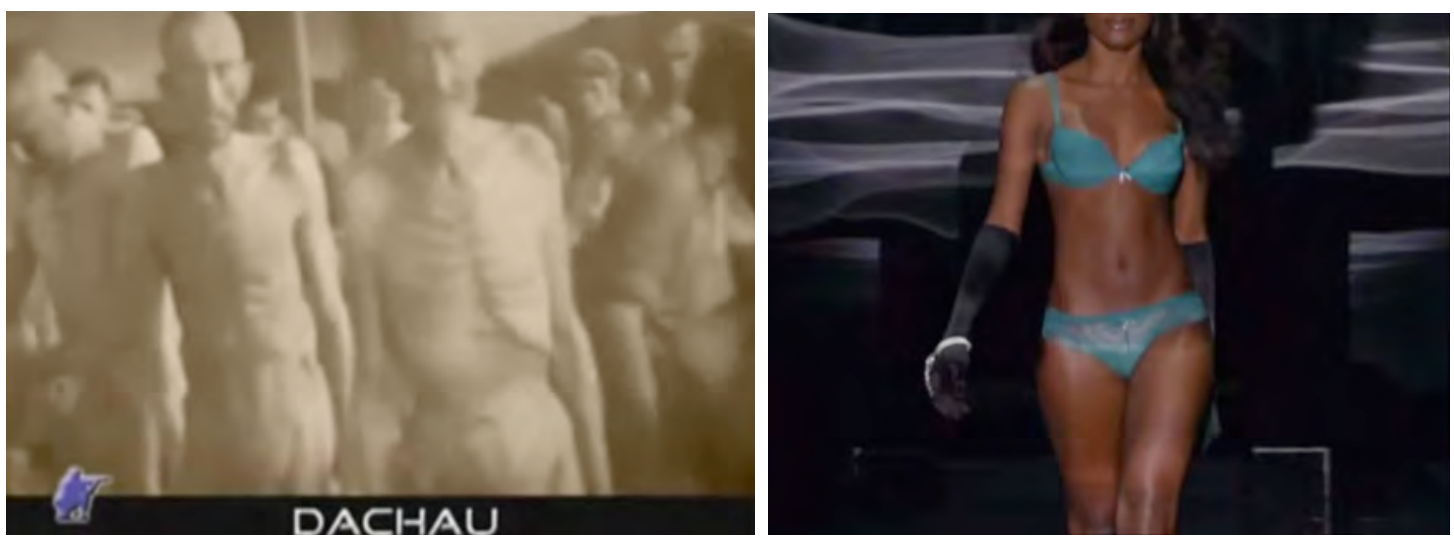

“La guerra y la moda”, María Perdiguero, VideoCollage, 2014.
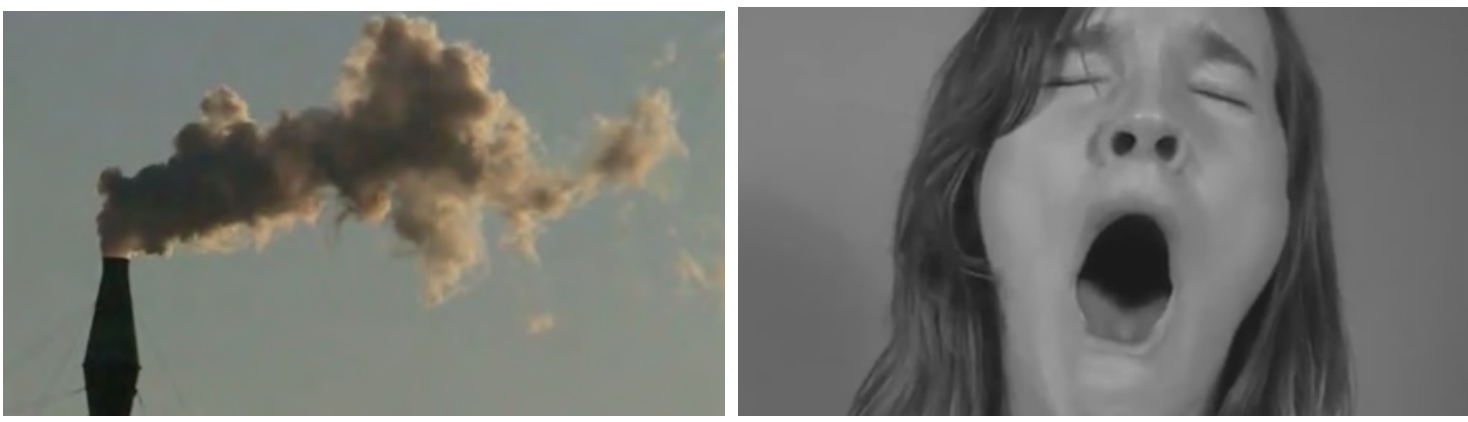

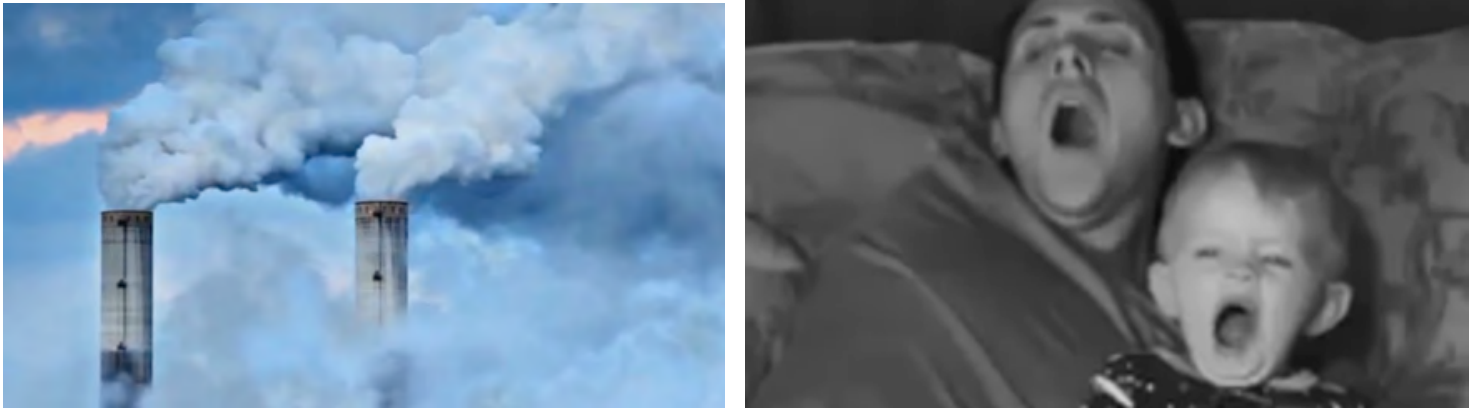

“Impasible", Yolanda Sánchez Ginestar, VideoCollage, 2014. https://youtu.be/WNkuZamvlEg
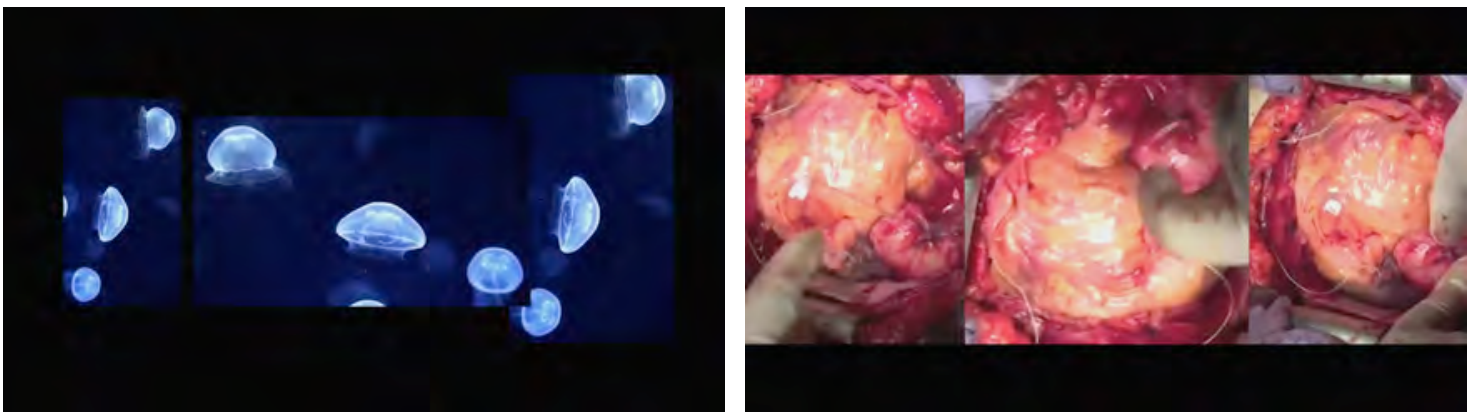

“Colusa”, Ana Domenech Saldaña, VideoCollage, 2015. https://youtu.be/O4H-2fKHTGQ

\section{CONCLUSIONES:}

El VideoCollage, una idea nacida como solución docente que permitiera a los estudiantes realizar su primera práctica de videocreación, ha devenido en una completa herramienta con la que introducirse en el mundo del videoarte, pues su simplicidad conceptual y técnica facilita la consecución de resultados interesantes a corto plazo.

La realización de un VideoCollage no requiere un conocimiento profundo de la técnica de edición de video, pero su práctica otorga a los estudiantes soltura en el manejo del software de edición y les motiva para seguir profundizando en este medio.

Las referencias históricas implícitas en esta práctica docente (Dadaísmo, apropiacionismo, experimentación cinematográfica, Teoría de la Gestalt, Poesía Experimental, Fluxus, etc. ) lo convierten en un medio útil para comprender la compleja genealogía de la Videocreación, así como algunos de los mecanismos básicos que la articulan: el montaje, el ritmo, la estructura, la semántica de la imagen y el sonido, etc.

Un resultado colateral de la metodología pautada para la realización del VideoCollage, es la aparición de semánticas inesperadas dotadas de una poética que difícilmente se hubiera podido conseguir con estrategias más "dirigidas".

La yuxtaposición de imágenes sin conexión aparente no garantiza la consecución de resultados artísticos notables, pero cuando estos aparecen, la poética audiovisual generada permite intuir el potencial experimental que encierra la práctica del VideoCollage.

La observación de los resultados prácticos del Videocollage, nos abre un nuevo objeto de investigación: por qué se producen esas sinergias. Las leyes de la Gestalt parecen ser esenciales en la interpretación de las relaciones formales y semánticas que se establecen entre las diferentes imágenes, pero intuimos la presencia de factores poéticos relacionados con la iconología, (simbolismo y semiótica) y con las nuevas sintaxis exploradas por la poesía experimental. 


\section{FUENTES REFERENCIALES}

JAKOBSON, ROMAN. Ensayos de lingüística general. Seix Barral, Barcelona 1975. ISBN: 978-84-322-0276-6.

SCHWITTERS, KURT. La poesía consecuente (Konsecuente Dichtung), 1924 Publicado en: G. Zeitschrift hir elementare Gestaltung, Berlín, 10 año, n.9 3, junio de 1924, IVAM, Valencia, 1995

TZARA, TRISTAN. Manifiesto sobre el amor débil y el amor amargo, VIII, en A l'antiphilosophe. En Littérature num. 15. Julio-Agosto de 1920.

FERRANDO, BARTOLOMÉ. El arte de la performance: elementos de creación, Editorial: Mahali Ediciones (Stella Cometa, S.L.), 2009. ISBN: 978-84-613-1524-6

MARINIELLO, SILVESTRA (1992). El cine y el fin del arte: teoría y práctica cinematográfica en Lev Kuleshov. Madrid: Cátedra. ISBN: 8437610699

KOHLER, WOLFANG. Gestalt psychology: an introduction to new concepts in modern psychology. New York: Liveright. Norton 1992 reprint: ISBN: 978-0871402189

BROSSA, JOAN. Brossa 1986-1991, poemas objeto e instalaciones [Exposición]; 30 enero-12 marzo, Sala Diputación de Huesca., Diputación de Huesca D.L. Huesca, 1991. ISBN: 84-86978-74-2

CABANNE, PIERRE. Conversaciones con Marcel Duchamp. Editorial Anagrama, Barcelona, 1972. ISBN: 9788493491659

PLANAS, EDUARD, “La poesia de l'escena”. En La revolta poética de Joan Brossa. Simposi internacional virtual i presencial dedicat a Joan Brossa. Fundació Joan Miró. Barcelona, 25-26 y 27 d’abril de 2001.

LEONE, GUILLERMO. Leyes De la Gestalt. 1998-2011. (Ref. de 10/05/2015) Disponible en Web: www. gestalt-blog.blogspot.com 


\section{ANEXO:}

Pautas para la Práctica del Videocollage tal como la reciben los estudiantes.

A lo largo de 3 cursos se pidió a los alumnos de la asignatura de Videoarte de la Facultad de Bellas Artes de Altea (UMH), un trabajo práctico en el que debían realizar una pieza de videocreación de 1 minuto de duración basada en el montaje por corte de varios clips de video de origen diverso.

Durante la experiencia, fuimos elaborando unas pautas básicas que clarificaban el proceso y que optimizaban tanto el flujo de trabajo como la posibilidad de obtener resultados con cierto valor artístico.

Éstas son esas pautas con las que los estudiantes deben jugar en el momento de abordar la realización de un VideoCollage:

A. Elección de dos conceptos temáticos muy alejados entre sí. No deben tener ninguna relación perceptible el uno con el otro. Los conceptos opuestos están relacionados entre sí, así que no son válidos en este proceso.

B. Realizar una búsqueda y descarga en "Youtube" de un mínimo de 4 vídeos distintos por concepto (total mínimo de videos: 8).

C. Realizar un montaje-collage aleatorio por corte con fragmentos extraídos de los videos descargados, yuxtaponiendo los 2 conceptos elegidos. Ensayar distintos ritmos de montaje durante la edición.

D. Análisis de los resultados: valoración de las nuevas semánticas encontradas, de los efectos rítmicos creados, del grado de interés de los clips de video utilizados y del audio resultante.

E. Si es preciso, y en pos de un resultado que podamos considerar "arte", remontaje del video aprovechando los descubrimientos semánticos y rítmicos encontrados y reelaborando adecuadamente el audio.

F. Tras añadir unos sencillos títulos de crédito iniciales y finales, en blanco sobre negro, exportación del montaje final con este formato: 1920 x 1080, progresivo, píxeles cuadrados, codec H.264.

G. Estas normas son de obligado cumplimiento, pero si el estudiante cree oportuno transgredirlas en algún momento del proceso, puede hacerlo siempre que argumente y justifique satisfactoriamente su decisión. 